\author{
Research Article
}

\title{
SURVEY ON PREVALENCE OF VEGADHARANA AS A RISK FACTOR FOR CARDIAC DISORDERS- AN OBSERVATIONAL PILOT STUDY
}

\section{Lolashri S.J ${ }^{*}$, Kiran M Goud ${ }^{2}$, Prasanna Kulkarni ${ }^{3}$}

${ }^{*}{ }_{1} \mathrm{PhD}$ Scholar, ${ }^{2}$ Professor, Department of PhD and P G Studies in Panchakarma, 3 Professor \& HOD, Department of Swasthavritta, Sri Kalabyraveshwara Swamy Ayurvedic Medical College, Hospital and Research Centre, Bangalore, Karnataka, India.

\section{Article info}

Article History:

Received: 28-10-2021

Revised: 08-11-2021

Accepted: 21-11-2021

KEYWORDS:

Cardiac disorders, MRFIT, Adharaneeya Vegas, Survey method.

\section{ABSTRACT}

The present era, which is a reflection of changing major driving forces such as social, economic and cultural due to globalization, urbanization and population ageing. By this change, there is raise in the prevalence of certain non-communicable diseases. Cardiac disorders are among such which stands first in increasing mortality rate about $31 \%$ globally. Now a day, the prevalence rate is increasing due to behavioral risk factors like tobacco use, unhealthy diet, obesity, physical inactivity, alcohol and smoking. People are also at higher risk of these disorders with the presence of high risk of one or more already established disease conditions like Hyperlipidemia, Hypertension, Diabetes mellitus etc. Indians are being affected by high rates of these major risk factors which are striking for cardiac disorders at an earlier age almost 33\% earlier than other demographical regions. Considering all these many organizations like MRFIT, American Heart association, National Lipid organization etc. are conducting various trials since four decades to establish the appropriate relation with risk factors to plan the better lines of management. Ayurveda explains about the concept of Dharaneeya and Adharaneeya vegas, where in Acharyas emphasize that many of the systemic diseases are caused by the forceful suppression of natural urges. Among 13 Dharaneeya vegas 9 are found to be the risk factors in causing various cardiac disorders. With this regard to explore and to assess the prevalence of Vegadharana as risk factor for cardiac disorders, an attempt has made as a pilot survey study on 40 cardiac patients. Aim: To understand the Prevalence and epidemiology of Vegadharana in Cardiac disorders. To observe the Co-relation between Vegadharana and Cardiac disorders. Methodology: It is a Pilot observational study done by using a survey strategy. The questionnaire method in an electronic format was used to collect the data. Descriptive statistics and Co-relation Co-efficient was used to analyze the data obtained. Result: In this Pilot study, the sum of the prevalence of Vegadharana was observed it was found that the frequency of Vegadharana was more in cardiac individuals, especially the category of few times and sometimes with $n$ value $=76$ and 64 respectively. Conclusion: With the above data, it can be concluded that; Vegadharana has an impact on the expectancy of cardiac disorders. The data also revealed the co-relation of Vegadharana in permutation which is signifying as higher risk factors in causing cardiac disorders.

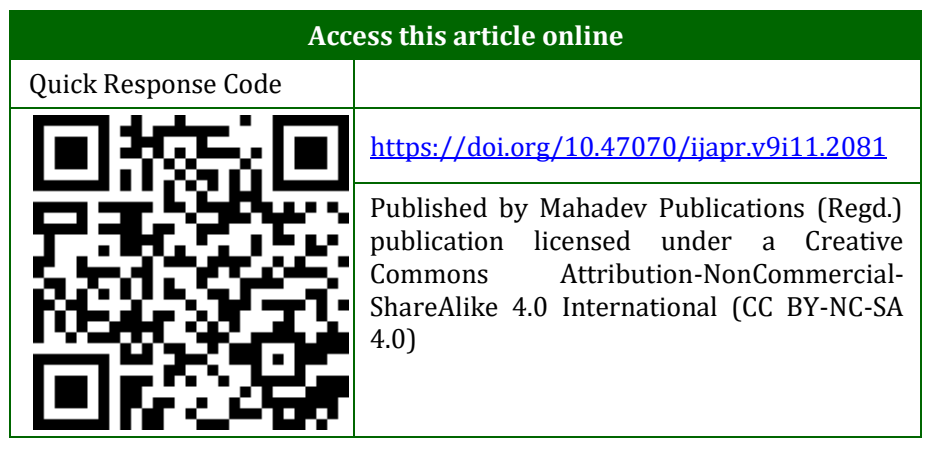

\section{INTRODUCTION}

Cardiac disorders are one such entity that ranks first in increasing mortality rate about $31 \%$ globally.[1] Now a day, the prevalence rate is increasing due to behavioral risk factors like tobacco use, unhealthy diet, obesity, physical inactivity, alcohol, and smoking.

People are also at elevated risk of these disorders with the presence of a high risk of one or more already established disease conditions like Hyperlipidemia, Hypertension, Diabetes mellitus, etc. 
Indians are being affected by high rates of these major risk factors which are striking for cardiac disorders at an earlier age almost 33\% earlier than other demographical regions. ${ }^{[2]}$

Ayurveda explains about the concept of Dharaneeya and Adharaneeya vegas, wherein Acharyas emphasize that many of the systemic diseases are caused by the forceful suppression of natural urges. [3]

Acharya Sushrutha while explaining the Nidanas of Hridroga the prime importance has been given to Vegadharana, ${ }^{[4]}$ supporting to this the same fact is found in Roganutpadaneeya adhyaya such that, among 13 Adharaneeya vegas 9 are found to be the risk factors in causing various cardiac disorders.

Hence to assess the prevalence of Vegadharana as a risk factor for cardiac disorders and to observe its co-relation, a pilot survey study was done by using the questionnaire method.

\section{Objectives of the Study}

- To understand the prevalence and epidemiology of Vegadharana in cardiac disorders.

- To observe the co-relation between Vegadharana and cardiac disorders.

\section{Methodology}

- This survey protocol was designed using guidelines pertaining to the conduct and reporting of survey studies.

\section{Study Design}

- This was an anonymous pilot observational study done by using a survey strategy.

- The questionnaire method in an electronic format was used to collect the data.

- Descriptive statistics and co-relation co-efficient was used to analyze the data obtained.

\section{Sampling Method}

- The convenience sampling technique was employed in the study.

\section{Sample Size}

- 80 voluntary individuals have participated in the survey. Among these 40 samples were cardiac individuals.

\section{Eligibility Criteria}

- Individuals who were suffering from any one of the cardiac disorders.

- Individuals of either sex, aged between 18-85 years.

\section{Observations}

Table 1: Prevalence of Age

\begin{tabular}{|c|c|c|}
\hline Age & No. of Patients & Percentage \\
\hline $26-35$ & 4 & $10 \%$ \\
\hline $36-45$ & 2 & $5 \%$ \\
\hline $46-55$ & 8 & $20 \%$ \\
\hline $56-65$ & 14 & $35 \%$ \\
\hline $66-75$ & 8 & $20 \%$ \\
\hline $76-85$ & 4 & $10 \%$ \\
\hline
\end{tabular}

In this study among 40 patients, 14 (35\%) were between the age group of 56-65 years, 8 (20\%) were in between each age group of 46-55 years and 66-75 years, $4(10 \%)$ were in between each age group of 26-35 years and 76-85 years, 2 (5\%) were in between $36-45$ years.

Table 2: Prevalence of Gender

\begin{tabular}{|c|c|c|}
\hline Gender & No. of Patients & Percentage \\
\hline Female & 10 & $25 \%$ \\
\hline Male & 30 & $75 \%$ \\
\hline
\end{tabular}

In this study, majority of the patients were male i.e.; 30 (75\%) and 10 (25\%) were female patients.

Table 3: Prevalence of Marital Status

\begin{tabular}{|c|c|c|}
\hline Marital status & No. of Patients & Percentage \\
\hline Married & 38 & $96 \%$ \\
\hline Unmarried & 1 & $2 \%$ \\
\hline Widower & 1 & $2 \%$ \\
\hline
\end{tabular}

In the study among 40 patients, 38 (96\%) were married, 1 (2\%) was unmarried and 1 (2\%) was widower.

Table 4: Prevalence of Socioeconomic Status

\begin{tabular}{|l|c|c|}
\hline $\begin{array}{l}\text { Socio economic } \\
\text { status }\end{array}$ & No. of Patients & Percentage \\
\hline Upper middle class & 16 & $45 \%$ \\
\hline Middle class & 22 & $55 \%$ \\
\hline Lower middle class & 2 & $5 \%$ \\
\hline
\end{tabular}

Among 40 patients, 22 (55\%) belonged to the middle class, $6(45 \%)$ belonged to the upper middle class and $2(5 \%)$ belonged to the lower middle class.

Table 5: Prevalence of Chronicity

\begin{tabular}{|c|c|c|}
\hline $\begin{array}{c}\text { Chronicity in } \\
\text { years }\end{array}$ & No. of Patients & Percentage \\
\hline $0.1-5$ & 21 & $52 \%$ \\
\hline $5.1-10$ & 9 & $22 \%$ \\
\hline $10.1-15$ & 5 & $13 \%$ \\
\hline $15.1-20$ & 1 & $3 \%$ \\
\hline $20.1-25$ & 4 & $10 \%$ \\
\hline
\end{tabular}

In this study among 40 patients, 21(52\%) were having chronicity in between $0.1-5$ years, $9(22 \%)$ in between the chronicity of 5.1-10 years, $5(13 \%)$ were in between the chronicity of 10.1-15 years, $4(10 \%)$ were in between the chronicity of 20.1-25 years and 1 (3\%) was between the chronicity of 15.1-20 years.

Table 6: Prevalence of Occupation

\begin{tabular}{|c|c|c|}
\hline Occupation & No. of Patients & Percentage \\
\hline Retired & 10 & $25 \%$ \\
\hline Business & 8 & $20 \%$ \\
\hline Home maker & 7 & $17.5 \%$ \\
\hline $\begin{array}{c}\text { Software } \\
\text { profession }\end{array}$ & 6 & $15 \%$ \\
\hline Farmer & 2 & $5 \%$ \\
\hline Labour & 2 & $5 \%$ \\
\hline Others & 5 & $12.5 \%$ \\
\hline
\end{tabular}

In this study among 40 patients, 10 (25\%) were retired individuals, 8 (20\%) were in business, 7 $(17.5 \%)$ were homemakers, $6(15 \%)$ were software 
professionals, $2(5 \%)$ were farmers, $2(5 \%)$ were labour and $5(12.5 \%)$ were in other professions. (i.e.,

Student-1, Teacher-1, Doctor-1, Pharmacist-1, Lawyer1)

Table 7: Prevalence of Vegadharana in Cardiac patients

\begin{tabular}{|c|c|c|c|c|}
\hline \multirow{2}{*}{$\begin{array}{c}\text { Prevalence of } \\
\text { Vegadharana }\end{array}$} & \multicolumn{5}{|c|}{ No. of Patients } \\
\cline { 2 - 5 } & Occasionally & Sometimes & Few times & Quite often \\
\hline Adhovata & 16 & 8 & 12 & 4 \\
\hline Vit & 14 & 8 & 13 & 5 \\
\hline Mutra & 9 & 6 & 16 & 9 \\
\hline Udgara & 28 & 5 & 4 & 3 \\
\hline Trishna & 18 & 11 & 8 & 3 \\
\hline Kaasa & 29 & 3 & 4 & 4 \\
\hline Shrama swasa & 23 & 9 & 6 & 2 \\
\hline Ashru & 22 & 8 & 7 & 3 \\
\hline Shukra & 23 & 6 & 6 & 5 \\
\hline
\end{tabular}

Figure 1: Prevalence of Vegadharana in Cardiac patients

\begin{tabular}{|c|c|c|c|c|c|c|c|c|c|}
\hline \multicolumn{10}{|c|}{ Vegadharana } \\
\hline \multirow{3}{*}{$\begin{array}{r}35 \\
30 \\
25 \\
20 \\
15 \\
10 \\
5 \\
0\end{array}$} & 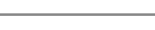 & - & . & $x^{2}$ & . & & & & \\
\hline & & & & & & & & & \\
\hline & Adhovata & Vit & Mutra & Udgara & Trishna & Kaasa & $\begin{array}{l}\text { Shrama } \\
\text { Shwasa }\end{array}$ & Ashru & Shukra \\
\hline$\square$ Occasionally & 16 & 14 & 9 & 28 & 18 & 29 & 23 & 22 & 23 \\
\hline$\square$ Sometimes & 8 & 8 & 6 & 5 & 11 & 3 & 9 & 8 & 6 \\
\hline$\square$ Fewtimes & 12 & 13 & 16 & 4 & 8 & 4 & 6 & 7 & 6 \\
\hline$\square$ Quite often & 4 & 5 & 9 & 3 & 3 & 4 & 2 & 3 & 5 \\
\hline
\end{tabular}

Among 40 patients; in Adhovata vegadharana, 16 were suppressing occasionally, 8 were suppressing sometimes, 12 were suppressing few times and 4 were suppressing quite often.

In Vit vegadharana, 14 were suppressing occasionally, 8 were suppressing sometimes, 13 were suppressing few times and 5 were suppressing quite often.

In Mutra vegadharana, 9 were suppressing occasionally, 6 were suppressing sometimes, 16 were suppressing few times and 9 were suppressing quite often.

In Udgara vegadharana, 28 were suppressing occasionally, 5 were suppressing sometimes, 4 were suppressing few times and 3 were suppressing quite often.

In Trishna vegadharana, 18 were suppressing occasionally, 11 were suppressing sometimes, 8 were suppressing few times and 3 were suppressing quite often.

In Kasa vegadharana, 29 were suppressing occasionally, 3 were suppressing sometimes, 4 were suppressing few times and 4 were suppressing quite often.

In Shrama shwasa vegadharana, 22 were suppressing occasionally, 8 were suppressing sometimes, 7 were suppressing few times and 3 were suppressing quite often.

In Ashru vegadharana, 16 were suppressing occasionally, 8 were suppressing sometimes, 12 were suppressing few times and 4 were suppressing quite often.

In Shukra vegadharana, 23 were suppressing occasionally, 6 were suppressing sometimes, 6 were suppressing few times and 5 were suppressing quite often.

\section{Adhovata Vegadharana}

Observations on Vegadharana in Comparison with Time Duration

Table 8: Observation on Adhovata Vegadharna in comparison with time duration

\begin{tabular}{|c|c|}
\hline Time duration & No. of Individuals \\
\hline$<15 \mathrm{~min}$ & 27 \\
\hline $15-30 \mathrm{~min}$ & 12 \\
\hline$>3 \mathrm{hrs}$ & 1 \\
\hline
\end{tabular}


Among 40 patients in Adhovata vegadharana majority i.e., 27 individuals were suppressing the urge less than 15 minutes, 12 were suppressing in between 15 minutes to 30 minutes and one was suppressing more than 3 hours.

Figure 8: Observation on Adhovata Vegadharna in Comparison with Time Duration

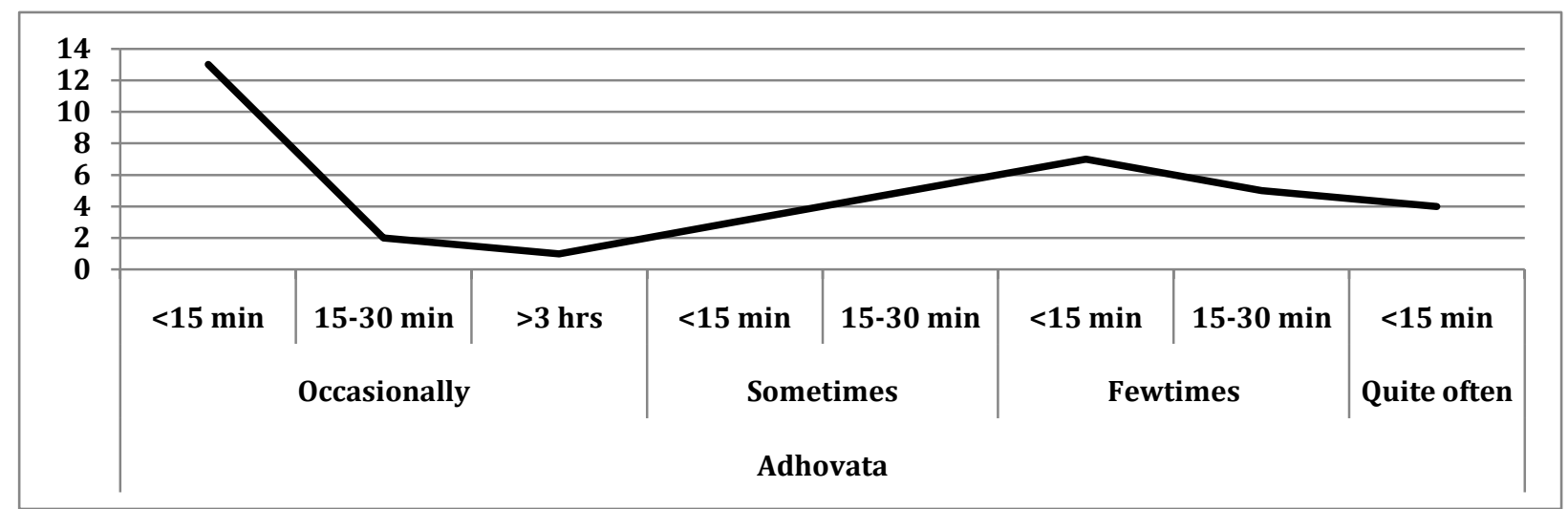

Vit Vegadharana

Table 9: Observation on Vit Vegadharna in Comparison with Time Duration

\begin{tabular}{|c|c|}
\hline Time Duration & No. of Individuals \\
\hline$<15 \mathrm{~min}$ & 14 \\
\hline $15-30 \mathrm{~min}$ & 17 \\
\hline $35-60 \mathrm{~min}$ & 4 \\
\hline$>1 \mathrm{hr} \&<3 \mathrm{hrs}$ & 4 \\
\hline$>3 \mathrm{hrs}$ & 1 \\
\hline
\end{tabular}

Among 40 patients in Vit vegadharana, the majority of them i.e., 17 individuals were suppressing the urge in between 15 minutes to 30 minutes, 14 were suppressing less than 15 minutes, 4 were suppressing in between 35 minutes to 60 minutes, 4 were suppressing more than 1 hour and less than 3 hours and 1 was suppressing more than 3 hours.

Figure 9: Observation on Vit Vegadharna in Comparison with Time Duration

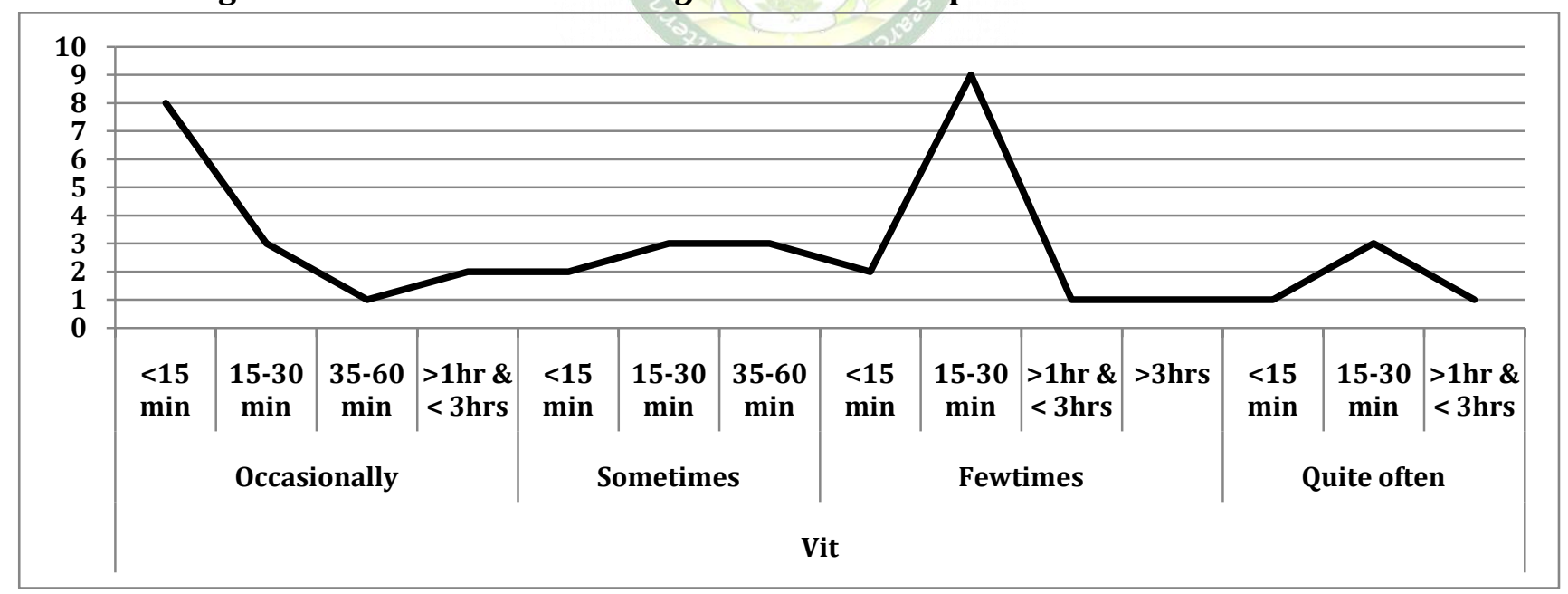

\section{Mutra Vegadharana}

Table 10: Observation on Mutra Vegadharna in Comparison with Time Duration

\begin{tabular}{|c|c|}
\hline Time duration & No. of Individuals \\
\hline$<15 \mathrm{~min}$ & 22 \\
\hline $15-30 \mathrm{~min}$ & 10 \\
\hline $35-60 \mathrm{~min}$ & 7 \\
\hline$>1 \mathrm{hr} \&<3 \mathrm{hrs}$ & 1 \\
\hline
\end{tabular}

Among 40 patients in Mutra vegadharana, majority of them i.e., 22 were suppressing the urge less than 15 minutes, 10 were suppressing in between 15 minutes to 30 minutes, 7 were suppressing in between 35 minutes to 60 minutes and 1 was suppressing more than 1 hour and less than 3 hours. 


\section{Figure 10: Observation on Mutra Vegadharna in Comparison with Time Duration}

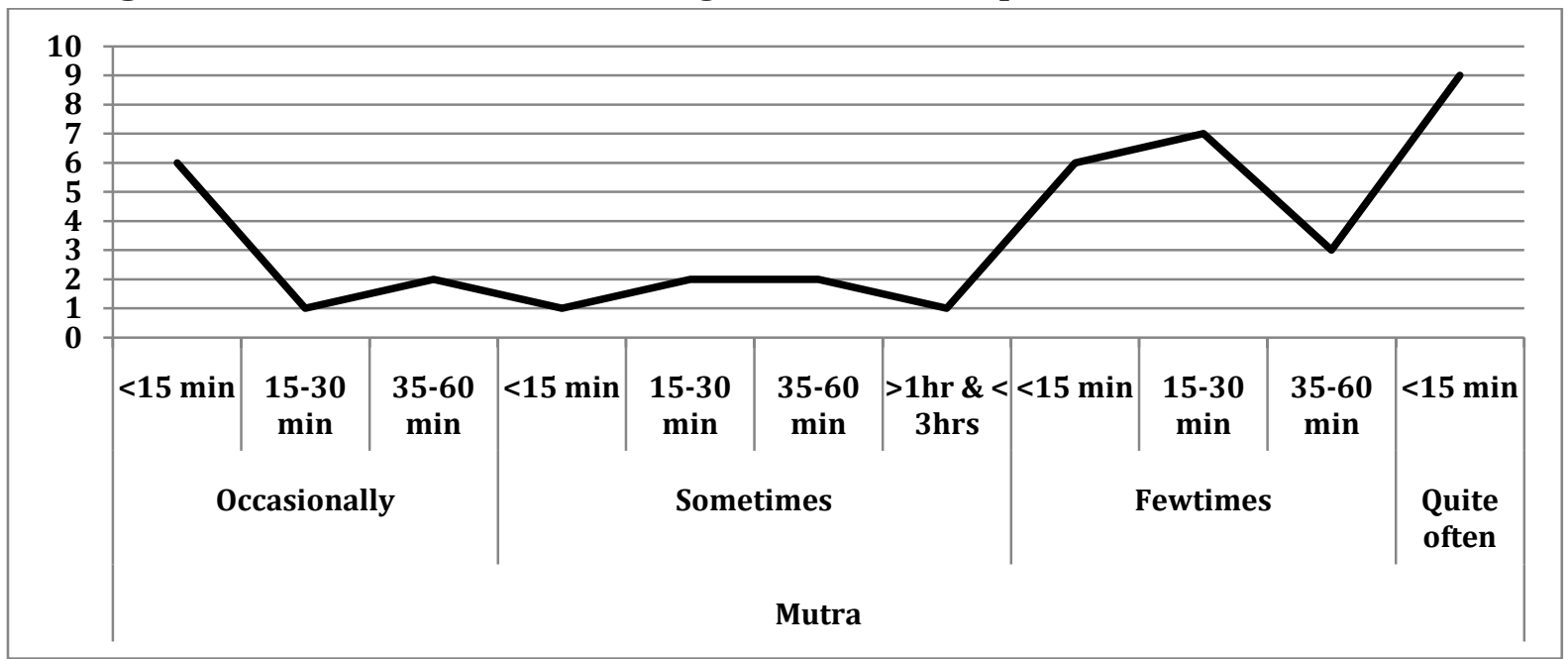

\section{Udgara Vegadharana}

Table 11: Observation on Udgara Vegadharna in Comparison with Time Duration

\begin{tabular}{|c|c|}
\hline Time duration & No. of Individuals \\
\hline$<30 \mathrm{sec}$ & 30 \\
\hline$<1 \mathrm{~min}$ & 4 \\
\hline$<2 \mathrm{~min}$ & 4 \\
\hline 2 min \& above & 2 \\
\hline
\end{tabular}

Among 40 patients in Udgara vegadharana, the majority of them i.e., 30 individuals were suppressing less than 30 seconds, 4 were suppressing less than 2 minutes, 4 were suppressing less than 1 minute and 2 were suppressing 2 minutes and above.

Figure 11: Observation on Udgara Vegadharna in Comparison with Time Duration

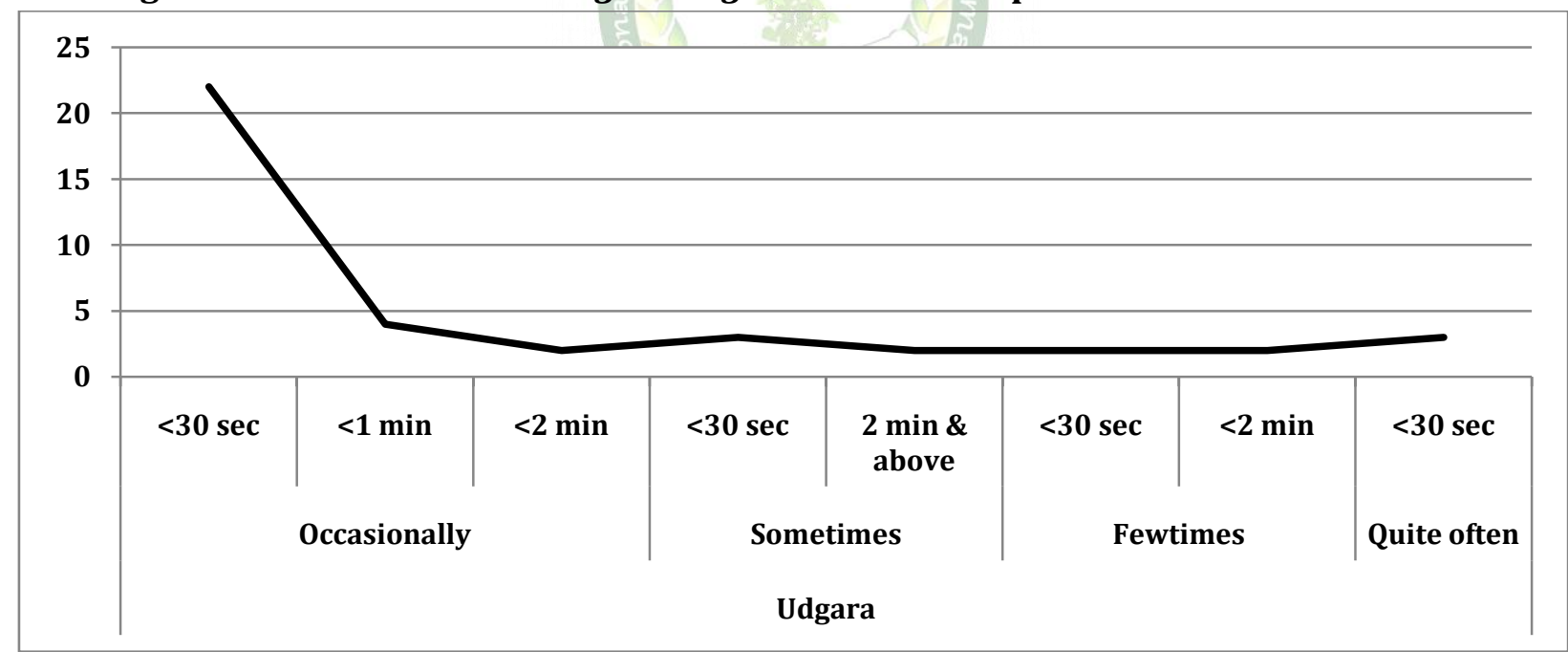

\section{Trishna Vegadharana}

Table 12: Observation on Trishna Vegadharna in Comparison with Time Duration

\begin{tabular}{|c|c|}
\hline Time duration & No. of Individuals \\
\hline$<30 \mathrm{~min}$ & 26 \\
\hline $30-60 \mathrm{~min}$ & 8 \\
\hline$>1 \mathrm{hr} \&<3 \mathrm{hrs}$ & 6 \\
\hline
\end{tabular}

Among 40 patients in Trishna vegadharana, the majority of them i.e.; 26 individuals were suppressing the urge less than 30 minutes, 8 were suppressing in between 30 minutes to 60 minutes and 6 were suppressing more than 1 hour and less than 3 hours. 
Figure 12: Observation on Trishna Vegadharna in Comparison with Time Duration

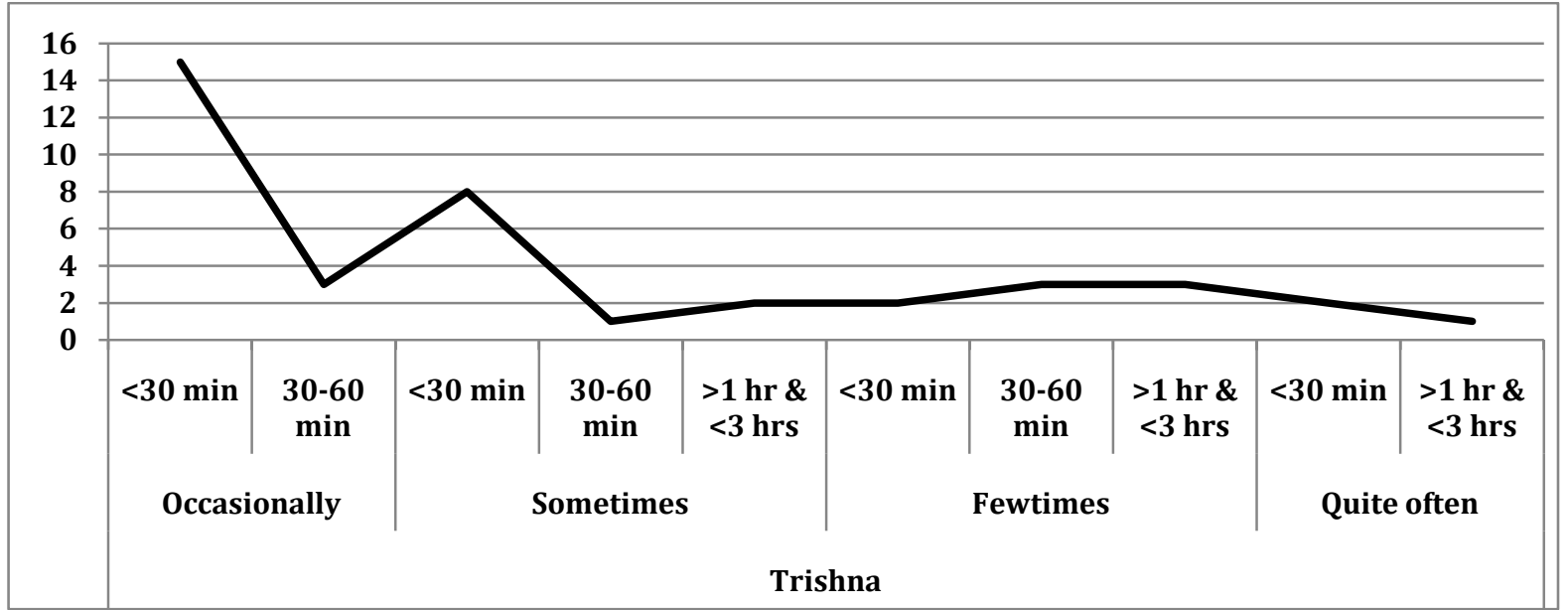

Kaasa Vegadharana

Table 13: Observation on Kaasa Vegadharna in Comparison with Time Duration

\begin{tabular}{|c|c|}
\hline Time duration & No. of Individuals \\
\hline$<1 \mathrm{~min}$ & 30 \\
\hline $1-5 \mathrm{~min}$ & 9 \\
\hline$>5 \mathrm{~min} \&<30 \mathrm{~min}$ & 1 \\
\hline
\end{tabular}

Among 40 patients in Kaasa vegadharna, the majority of them i.e., 30 individuals were suppressing the urge less than 1 minute, 9 were suppressing in between 1 minute to 5 minutes and 1 was suppressing more than 5 minutes and less than 3 minutes.

\section{Figure 13: Observation on Kaasa Vegadharna in Comparison with Time Duration}

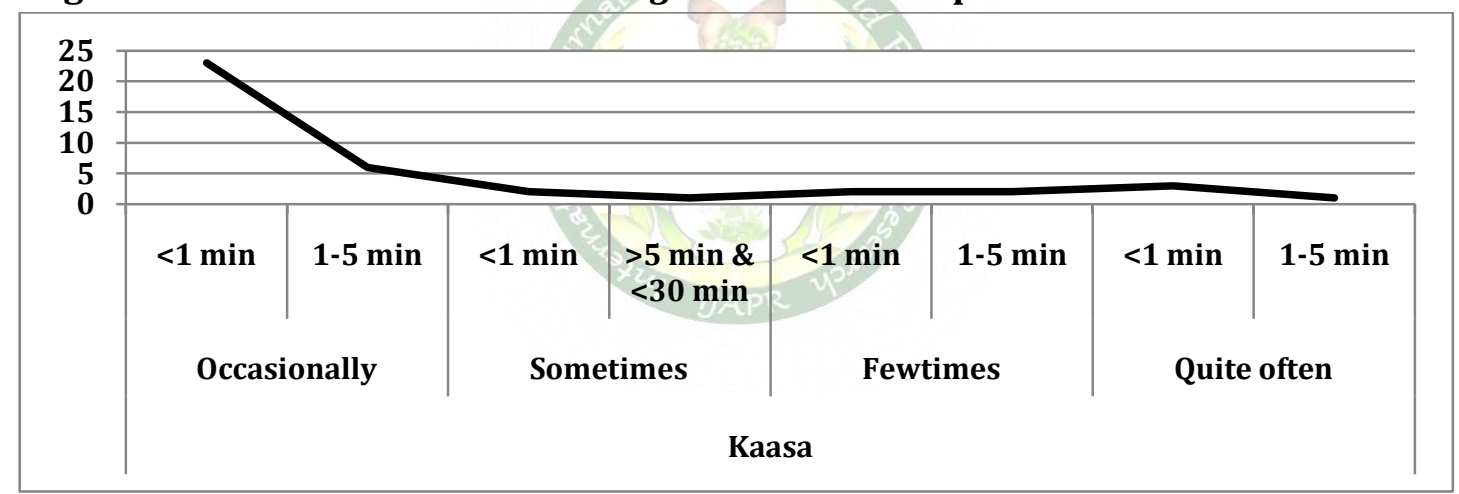

\section{Shrama Shwasa Vegadharana}

Table 14: Observation on Shrama Shwasa Vegadharna in Comparison with Time Duration

\begin{tabular}{|c|c|}
\hline Time duration & No. of Individuals \\
\hline$<30 \mathrm{sec}$ & 30 \\
\hline $1-5 \mathrm{~min}$ & 9 \\
\hline
\end{tabular}

Among 40 patients in Shrama shwasa vegadharana, the majority of them i.e., 30 were suppressing the urge less than 30 seconds and 10 were suppressing in between 1 minute to 5 minutes.

Figure No.14: Observation on Shrama Shwasa Vegadharna in Comparison with Time Duration

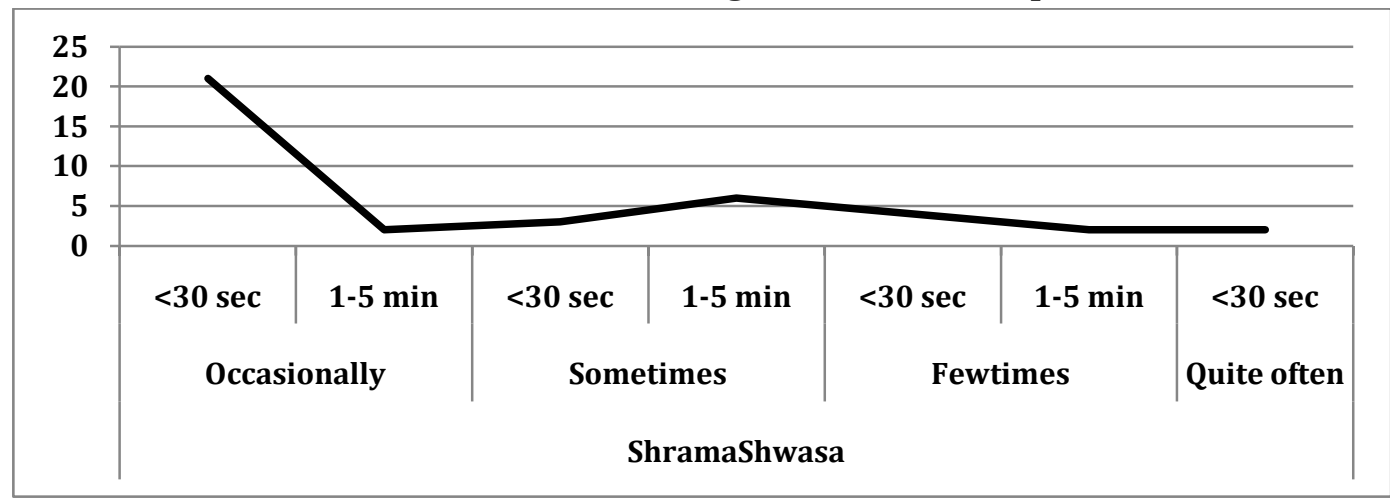




\section{Ashru Vegadharana}

Table 15: Observation on Ashru Vegadharna in Comparison with Time Duration

\begin{tabular}{|c|c|}
\hline Time duration & No. of Individuals \\
\hline$<30 \mathrm{~min}$ & 28 \\
\hline $30-60 \mathrm{~min}$ & 4 \\
\hline$>1 \mathrm{hr} \&<6 \mathrm{hrs}$ & 7 \\
\hline$>12 \mathrm{hrs}$ & 1 \\
\hline
\end{tabular}

Among 40 patients in Ashru vegadharana, the majority of them i.e., 28 individuals were suppressing the urge less than 30 minutes, 7 were suppressing in between more than 1 hour and less than 6 hours, 4 were suppressing in between 30 minutes to 60 minutes and 1 was suppressing more than 12 hours.

Figure 15: Observation on Ashru Vegadharna in Comparison with Time Duration

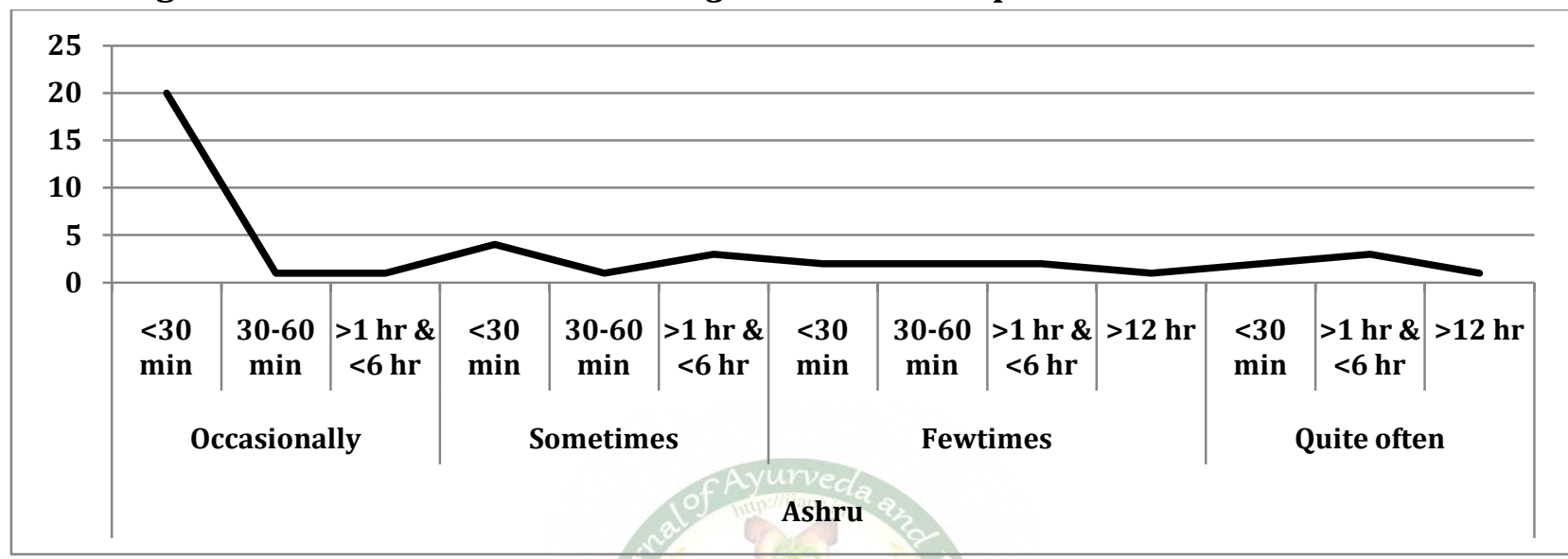

Among 40 patients in Ashru vegadharana, the majority of them i.e.; 28 individuals were suppressing the urge less than 30 minutes, 7 were suppressing in between more than 1 hour and less than 6 hours, 4 were suppressing in between 30 minutes to 60 minutes and 1 was suppressing more than 12 hours.

\section{DISCUSSION}

In this pilot study among 80 participants, 40 samples were cardiac individuals. When the sum of the prevalence of Vegadharana was observed it was found that the frequency of Vegadharana was more in cardiac individuals, especially the category of few times and sometimes with $\mathrm{n}$ value $=76$ and 64 respectively. This data is suggesting that; Vegadharana has an impact on the expectancy of cardiac disorders. The data also revealed the co-relation of Vegadharana in permutation which is signifying as higher risk factors in causing cardiac disorders. i.e., Kaasa with Udgara CC value -0.68, Mutra with Vit - CC value - 0.61, Shrama shwasa with Udgara - CC value - 0.52, Mutra with Udgara, - CC value - 0.5, Vit with Shrama shwasa - 0.48, Adhovata with Mutra - 0.47.

In our classics Acharyas, while explaining the Nidanas of Hrudroga the prime importance has been given to Vegadharana also. Thus, this evidence is giving an insight about the impact of Vegadharana in cardiac individuals as the same observed in the above study.

The Vegas are function of Vatadosha, hence Vegavarodha is at the first instance vitiates Vata dosha and causes its Prakopa. This observational study gives a lead regarding the involvement of Vata where there will be a disturbance in the physiological functions of Vata, especially the Prana vayu and Vyana vayu. There is the involvement of Pranavaha srotas, Mahasrotas, Rasavahadhamani, Rasavaha, Raktavaha srotas which are with the Moola of Hrudaya, where Acharya Chakrapani commented Moola as 'Prabhava sthana'. Thus, if there is Vegadhara for a longer duration, it leads to the impairment in physiological aspects of Hrudaya. Also opined that Pranavahasrotas is the Vayu vishista srotas where in general Vayu is considered as the Dhamani all over the body. [5]

Hrudaya is the seat of Vyana vata, where it controls the Gati of Hrudaya, this may be compared with the conduction system of the heart, and hence any derangement in the function of Vyana vata may lead to cardiac disorders. On the contemporary, this Vyana vata can be understood as autonomic outflow (both sympathetic and parasympathetic).

In Mutravegadharana purishavegadharana there is the involvement of Mutravaha and Purishavaha srotas. Adhovata, Mutra, Purisha rodha lead to Udavarta, which generates pressure on the diaphragm, Hrudaya which results in the initiation of symptoms of cardiac disorders. Vegadharana precipitates increase the frequency and intensity of straining for defecation and urination. This means an increase in the frequency of effect of Valsalva maneuver by there will be reduction in the sympathetic nervous system arousal 
and increases the parasympathetic outflow. Also, this Valsalva maneuver adversely affecting the cardiovascular system which may result in syncope or even death. ${ }^{[6]}$

Hypothetically, Trishna vegadharana might produce Ap-kshaya, where there will be a decrease in Dravata and increase in Guruta and Picchilata of Rakta which might be accused of cardiac disease. Meanwhile, Ashruvegadharana leads to psychological stress, which has the potential to disturb autonomic nervous system flow in the body and may lead to acute or chronic psychic or somatic disturbance which may be associated with tachycardia, restlessness, etc.

In nutshell, Vegadharana is associated with Vataprakopa in other turn disturbance in autonomic and limbic functions of the nervous system, which are potent enough in altering the physiological functions of the cardiovascular system.

\section{CONCLUSION}

Though this survey pilot study fulfilled the objectives mentioned, there were certain limitations in this protocol, where the data obtained with the questionnaire made for this survey was limited. Also few of the responses through the electronic method adopted here to collect the data with voluntary participants were not satisfactory. The response regarding the Shukravegadharana was also not satisfactory.

Thus, further study should be conducted with larger sample size, with the inclusion of retrospective data, as well as including other data collection methods and adopting certain cardiac biomarkers, parameters of Pranavahasrotas, Manovahasrotas will give still more clear insights about the prevalence of Vegadharana as a risk factor in cardiac disorders.

\section{REFERENCES}

1. The changing patterns of cardiovascular diseases and their risk factors in the states of India: the Global Burden of Disease Study 1990-2016, Volume 6, Issue 12, Published on September11, 2018 DOI: https://doi.org/10.1016/S2214109X(18)30407-8.

2. Samah Alageel et al. Changes in cardiovascular disease risk and behavioural risk factors before the introduction of a health check up programme in England, Volume 91, October 2016, pg no-158-163, https://doi.org/10.1016/j.ypmed.2016.08.025.

3. Vagbhata, Astanga Hrudaya, Sarvanga Sundara Commentary of Arunadatta and Ayurveda Rasayana Commentary of Hemadri, edited by; Pandit Hari Sadasiva Sastri Paradikara Bhisagacharya, Choukambha Surabharati Prakashan, Varanasi, reprint-2010, Sutra Sthana, 4th Chapter, Verse-2-21 Pp: 956, pg no-53-56.

4. Sushruta, Sushruta Samhita, Nibandha Samgraha Commentary of Sri Dalhanacharya and Nyaya Chandrika Panjika on Nidanasthana Commentary of Sri Gayadasacharya, by; Vaidya Yadavji Trikramji Acharya Varanasi, Choukambha Surabharati Prakashan, reprint-2008, Uttaratantra, 43 Chapter, Verse-3, Pp: 824, pg no-727.

5. Agnivesha, Charaka Samhita, Ayurveda Deepika Commentary of Chakrapani, edited by; Vaidya Yadavji Trikramji Acharya, Choukambha Surabharati Prakashan, Varanasi, reprint- 2011, Vimana Sthana, $5^{\text {th }}$ Chapter, Verse-8, Pp: 738, pg no-251.

6. Fuyou Liang et al, Simulation of hemodynamic responses to the valsalva maneuver: an integrative computational model of the cardiovascular system and the autonomic nervous system, Volume 56, Issue 1, Feburary 2006, pg no-45-65, doi: 10.2170/physiolsci.rp001305.

\section{Cite this article as:}

Lolashri S.J, Kiran M Goud, Prasanna Kulkarni. Survey on Prevalence of Vegadharana as a Risk Factor for Cardiac Disorders- An Observational Pilot Study. International Journal of Ayurveda and Pharma Research. 2021;9(11):39-46.

https://doi.org/10.47070/ijapr.v9i11.2081 Source of support: Nil, Conflict of interest: None Declared
*Address for correspondence

Dr. Lolashri

PhD Scholar,

Dept. of PhD Studies in Panchakarma,

Sri Kalabyraveshwara Swamy

Ayurvedic Medical College, Hospital

and Research Centre, Bangalore,

Karnataka, India.

Ph: 9738671971

Email: sjlolashri@gmail.com

Disclaimer: IJAPR is solely owned by Mahadev Publications - dedicated to publish quality research, while every effort has been taken to verify the accuracy of the content published in our Journal. IJAPR cannot accept any responsibility or liability for the articles content which are published. The views expressed in articles by our contributing authors are not necessarily those of IJAPR editor or editorial board members. 